\title{
Single well control area splitting method based on reservoir physical properties and gas well productivity differences
}

\author{
Wang Chunpu ${ }^{1, \mathrm{a}^{*}}$ \\ ${ }^{1}$ Research Institute of Geological Exploration and Development, CNPC Chuanqing Drilling Engineering Co., Ltd.,Chengdu, Sichuan \\ 610051, China
}

\begin{abstract}
The determination of the control area of a single well is the prerequisite for the evaluation of the reserves of a single well. The current calculation methods of the control area of a single well are mainly divided into: experience formula, area balancing method, and the physical model, in order to solve the different limitations of the existing single-well control area splitting method and the problem of large error in use, this paper puts forward a kind of based on gas reservoir physical property and the growth of single well productivity difference algorithm for single well control area is split, according to the results of the split combining static reservoir parameters, using volumetric method for single well and the calculation of reserves of gas reservoir evaluation, further clarify the original and the remaining gas distribution of gas reservoir, for the subsequent reasonable development of the gas reservoir and enhance oil recovery. In this paper, block $\mathrm{S}$ of Sulige gas field is taken as an example, and the geological reserve of block is calculated as $354.75 \times 10^{8} \mathrm{~m}^{3}$, compared with the basic proven reserves of Block S, $364.84 \times 10^{8} \mathrm{~m}^{3}$, the error is $2.61 \%$ and the reliability is strong.
\end{abstract}

\section{Preface}

With the development of gas reservoirs, in order to further clarify the remaining geological reserves and the distribution of remaining oil and gas on the plane well points, it is necessary to calculate the geological reserves of a single well, and the calculation of the control area of a single well is the top priority of determining the geological reserves of a single well. In general, the current methods for calculating the control area of a single well are mainly divided into three types: empirical formula method ${ }^{[1-3]}$, area trade-off method ${ }^{[4-7]}$, and physical model ${ }^{[8-10]}$. Among them, the empirical formula method uses pressure recovery well testing as a means to obtain calculation data, but for low-permeability gas wells, the pressure recovery time is long and it is difficult to obtain accurate data; the area trade-off method is based on the triangulation algorithm, but it believes that single well control The range is within $1 / 2$ of the distance between adjacent wells, and the influence of the heterogeneity of the actual gas reservoir on the control area of a single well is not considered, which is contrary to the actual situation; the physical model method uses the logging interpretation data to perform geological modeling. The established model requires high accuracy, complicated process and complicated operation.

Based on the splitting basis of gas well test productivity and gas reservoir physical parameters, this paper proposes a single well control area splitting method based on growth factors, which is useful for verification of reserves based on the area splitting results.

\section{Theoretical basis}

Based on the theory of unstable well test pressure transmission, the control area of a single well is divided by the first contact position of the pressure wave of two wells, as shown in Figure 1.
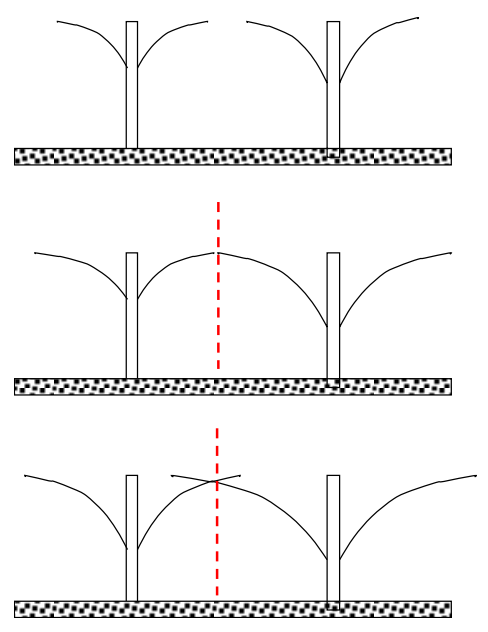

Figure 1 Schematic diagram of pressure wave conduction

\footnotetext{
* Corresponding author: ${ }^{a}$ wangchp_dyy $@$ cnpc.com.cn
} 


\section{Splitting method}

\subsection{Splitting principle}

Firstly, the gas reservoir is gridded, centered on each well point, according to the fair growth factor algorithm, ignoring the heterogeneity of the gas reservoir and the difference of single wells, growing to the surrounding adjacent grid, and each time it is grown, it is judged whether the growth point is with the boundary Intersect until the growth of the entire gas reservoir is completed (Figure 2). The numbers in the figure represent the position of pressure conduction at different time steps.

\begin{tabular}{|l|l|l|l|l|l|l|l|}
\hline 1 & 1 & 1 & 2 & 3 & 4 & 5 & 5 \\
\hline 1 & $\mathrm{~A}$ & 1 & 2 & 3 & 4 & 4 & 4 \\
\hline 1 & 1 & 1 & 2 & 3 & 3 & 3 & 3 \\
\hline 2 & 2 & 2 & 2 & 2 & 2 & 2 & 2 \\
\hline 3 & 3 & 3 & 2 & 1 & 1 & 1 & 2 \\
\hline 4 & 4 & 3 & 2 & 1 & $\mathrm{~B}$ & 1 & 2 \\
\hline 5 & 4 & 3 & 2 & 1 & 1 & 1 & 2 \\
\hline 5 & 4 & 3 & 2 & 2 & 2 & 2 & 2 \\
\hline
\end{tabular}

Figure 2 Schematic diagram of fair growth factor algorithm

There are two wells A and B in the figure. Regardless of the heterogeneity of their gas reservoirs, if the productivity of the two wells is the same, the growth rate of the gas well is the same. The splitting results are shown in Figure 2.

However, actual gas reservoirs always have heterogeneity and gas well productivity differences. In order to better fit the actual situation, a differentiated growth factor algorithm is further proposed. The growth factor is used to control the growth rate of a single well, and the growth factor is:

$$
G_{\mathrm{f}}=q_{\mathrm{sd}} \sqrt{\frac{K}{\mu \phi C_{\mathrm{t}}}}
$$

Based on the above growth factor calculation equation, when the growth factor of the two wells A and $\mathrm{B}$ is $1: 2$, the schematic diagram of the single well control area split under the differential growth factor algorithm (Figure 3),

\begin{tabular}{|l|l|l|l|l|l|l|l|}
\hline 1 & 1 & 1 & 2 & 3 & 3 & 3 & 3 \\
\hline 1 & $\mathrm{~A}$ & 1 & 2 & 2 & 2 & 2 & 2 \\
\hline 1 & 1 & 1 & 2 & 2 & 2 & 2 & 2 \\
\hline 2 & 2 & 2 & 1 & 1 & 1 & 1 & 1 \\
\hline 3 & 2 & 2 & 1 & 1 & 1 & 1 & 1 \\
\hline 3 & 2 & 2 & 1 & 1 & $\mathrm{~B}$ & 1 & 1 \\
\hline 3 & 2 & 2 & 1 & 1 & 1 & 1 & 1 \\
\hline 3 & 2 & 2 & 1 & 1 & 1 & 1 & 1 \\
\hline
\end{tabular}

Figure 3 Schematic diagram of differential growth factor algorithm

\subsection{Splitting process}

Based on the above-mentioned differential growth factor algorithm, using Matlab mathematical software, a single well control area splitting program is compiled.

First, prepare static and dynamic parameters of gas reservoirs and gas wells, including actual gas reservoir area, logging data, reservoir temperature, gas viscosity, gas deviation factor, gas reservoir radius, wellbore radius, well position coordinates, boundary coordinates, Single well productivity; reduce the scale of boundary coordinates;

Second, according to the boundary coordinates of a single well, use the triangulation algorithm to extract the boundary of discrete points and draw the boundary curve of the gas reservoir block;

Third, based on single-well logging data, a twodimensional matrix of gas reservoir physical properties and a two-dimensional matrix of reservoir effective thickness are established through programming, and the porosity calculation formula is used to further calculate the two-dimensional matrix of porosity;

Fourth, according to the established two-dimensional permeability matrix, the two-dimensional matrix of effective reservoir thickness, and the two-dimensional matrix of porosity, combined with the single-well productivity data, the single-well competition coefficient equation is used to calculate the single-well competition coefficient;

Fifth, according to the well location coordinates and boundary curves, combined with the obtained single well competition coefficient, intelligent splitting of the gas reservoir single well control area;

Sixth, when no point in the gas reservoir satisfies the growth point discriminant formula, the calculation is terminated, and the single well area split map of the gas reservoir is obtained. According to the single well area split result of the gas reservoir, the control area ratio of each single well is obtained, combined with the gas reservoir The actual gas-bearing area is calculated to obtain the control area of each single well.

\subsection{Splitting results}

According to the above-mentioned single well control area splitting method based on the differential growth factor algorithm, to calculate the single well control area, the single well control area split map (turtle diagram) as shown in the figure can be obtained (Figure 4).

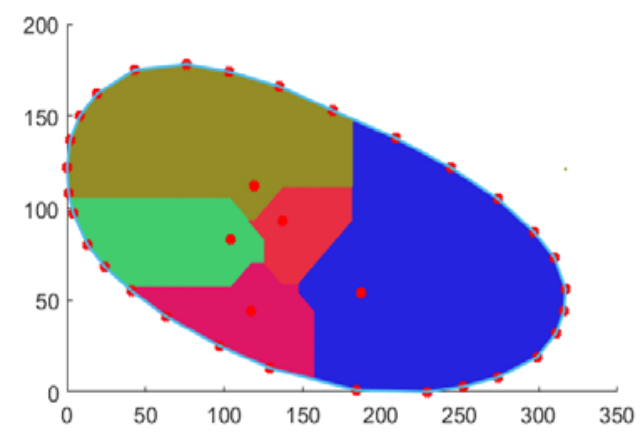

Figure 4 Splitting results of single well control area 
Combining the above figure, using the compiled program can get the area proportion of each well point (Table 1).

Table 1 The proportion of single well controlled area

\begin{tabular}{|c|c|c|}
\hline Abscissa & Y-axis & Single well control area ratio \\
\hline 16568648 & 4139196 & 15303 \\
\hline 16568384 & 4139989 & 19374 \\
\hline 16569034 & 4140186 & 9341 \\
\hline 16570030 & 4139404 & 66375 \\
\hline 16568673 & 4140568 & 43663 \\
\hline
\end{tabular}

Combining the actual gas reservoir block area, the actual control area of each single well can be obtained according to the proportion of single well control area.

\section{Case demonstration}

Based on the above-mentioned differential growth factor splitting method and single well reserve abundance evaluation method, combined with tight sandstone gas reservoir S block for corresponding calculation. There are a total of 132 production wells in Block S. Combining the static parameters of the reservoir (Table 2) and the splitting results of the control area of a single well in Block $\mathrm{S}$ are as follows (Figure 5), the actual control area of a single well is further obtained (Table 3 ).

Table 2 Some single well static parameters and control area

\begin{tabular}{|c|c|c|c|c|c|c|}
\hline $\begin{array}{c}\text { Well } \\
\text { name }\end{array}$ & Abscissa & Y-axis & $S_{\mathrm{w}}$ & $\phi / \%$ & $h / \mathrm{m}$ & $\begin{array}{c}\text { Test } \\
\text { capacity } \\
/ 10^{4} \mathrm{~m}^{3}\end{array}$ \\
\hline S10-43 & 19237061 & 4267494 & 0.64 & 8.10 & 17.1 & 3.3 \\
\hline S10-49 & 19241558 & 4267200 & 0.69 & 7.90 & 19.6 & 4.1 \\
\hline S10-51 & 19243265 & 4267452 & 0.63 & 7.51 & 13.7 & 1.8 \\
\hline S10-53 & 19244432 & 4267448 & 0.70 & 0.13 & 8.9 & 3.4 \\
\hline S11-42 & 19236587 & 4265868 & 0.64 & 9.26 & 8.9 & 1.6 \\
\hline S11-43 & 19236626 & 4266660 & 0.75 & 8.91 & 3.2 & 1.9 \\
\hline S11-50 & 19242183 & 4266299 & 0.71 & 8.08 & 6.4 & 2.2 \\
\hline S11-51 & 19242711 & 4265930 & 0.7 & 6.31 & 8.4 & 3.6 \\
\hline S12-39 & 19233028 & 4265393 & 0.69 & 7.05 & 11.4 & 4.4 \\
\hline S12-42 & 19235273 & 4264845 & 0.72 & 6.70 & 5.5 & 3.9 \\
\hline
\end{tabular}

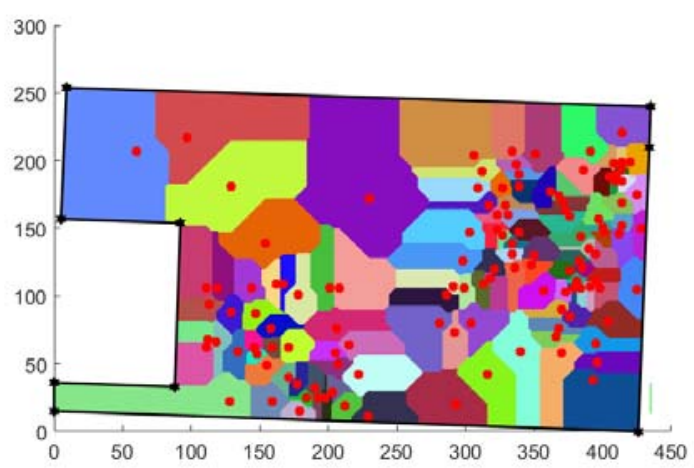

Figure. 5 Split diagram of single well control area in block $\mathrm{S}$

Based on the gas-bearing area data of $856.98 \mathrm{~km}^{2}$ in the whole area, combined with Matlab splitting results, the actual control area of each single well is obtained (Table 3).

Table 3 Actual control area of some single wells

\begin{tabular}{|c|c|c|c|}
\hline Well name & $\begin{array}{c}\text { Matlab grid } \\
\text { number }\end{array}$ & Area ratio & $\begin{array}{c}\text { Single well gas } \\
\text { area } / \mathrm{km}^{2}\end{array}$ \\
\hline S10-43 & 384 & 0.004107 & 3.52 \\
\hline S10-49 & 367 & 0.003925 & 3.36 \\
\hline S10-51 & 153 & 0.001636 & 1.40 \\
\hline S10-53 & 370 & 0.003957 & 3.39 \\
\hline
\end{tabular}

\begin{tabular}{|c|c|c|c|}
\hline S11-42 & 185 & 0.001979 & 1.70 \\
\hline S11-43 & 113 & 0.001209 & 1.04 \\
\hline S11-50 & 155 & 0.001658 & 1.42 \\
\hline S11-51 & 289 & 0.003091 & 2.65 \\
\hline S12-39 & 1277 & 0.013658 & 11.70 \\
\hline S12-42 & 289 & 0.003091 & 2.65 \\
\hline
\end{tabular}

Based on the above-mentioned single well control area splitting results, combined with the single well porosity, layer thickness, and saturation data, the geological reserves of the single well are obtained, and the geological reserves of the whole area are further obtained as $354.75 \times 10^{8} \mathrm{~m}^{3}$. The proven geological reserves of the block are $364.38 \times 10^{8} \mathrm{~m}^{3}$, the error is $2.61 \%$, the model is reliable, and this method has great practicability.

\section{Conclusion}

Based on previous research, this paper proposes a growth factor single-well control area splitting method, which fully considers the influence of reservoir heterogeneity and gas well productivity differences on the single-well control area. By adopting the $\mathrm{S}$ area of tight sandstone gas reservoirs Block as an example, the control area of each single well is obtained by this method, combined with logging interpretation data, the volume method is used to calculate the geological reserves, and the numerical simulation of the geological reserves in the $\mathrm{S}$ block is compared. The error is $2.61 \%$. This method has good practicability.

\section{Acknowledgments}

This paper is one of the phased achievements of the Joint Research Institute of Southwest Petroleum University and Chuanqing drilling Engineering Company in 2019,

Study on gas water seepage mechanism and water control countermeasures in Su 59 block (CQXN-2019$07)$.

\section{References}

1. LI M, Yang Y.(1994) Discussing on dynamic reserve of low permeability gas reservoir calculated by pressure build-up data[J], Natural Gas Industry, 1994(03):36-38+99-100.

2. Xu J P. (1995) Determination of average formation pressure and effective radius of single well control[J]. Well Testing, 1995(02): 31-35. M. Ben Rabha, M.F. Boujmil, M. Saadoun, B. Bessaïs, Eur. Phys. J. Appl. Phys. (to be published)

3. Ma Z X, Jia Z Q, Ye X C, et al. (2010) Study on calculation method of single well controlled reserves in Sulige gas field[J]. Petrochemical Industry Application, 29(Z1):98-101+125.

4. He D B, Wang L J, Ji G, et al. (2012) Well spacing optimization for Sulige tight sand gas field,NW China[J]. Petroleum Exploration and Development, 39(04):458-464. 
5. Delanuay.(1934) "Sur la sphere vide" lzvestiya Akademii Nauk [J]. USSR, Math and Nat Sci Div, No.6: 793-800.

6. Xu C H, Fan X T, Chi J P, et al. (2005) Calculation of single well geological reserves by area trade-off splitting method[J]. Special Oil \& Gas Reservoirs, 2005(02): 45-48+106.

7. Jiang W B, Mo R J, Zhang Y J, et al. (2013) Optimization of improved Voronoi diagram in calculating oil and gas reserves parameters[J]. Complex Hydrocarbon Reservoirs, 6(02): 7-9.

8. Zhang X B, Feng J, Song J T, et al. (2018) Study on remaining oil distribution characteristics of Chang 6 reservoir in ZW block by well control area $\operatorname{method}[\mathrm{J}]$. Petrochemical Industry Technology, 25(11): 143-144.

9. Gao S S, Liu H X, Ye L Y, et al. (2019) A new method for well pattern density optimization and recovery factor evaluation of tight sandstone gas reservoirs[J]. Natural Gas Industry, 39(08):58-65.

10. HOU K F, LI J B, ZHANG J, et al. (2020) Evaluation and development countermeasures of undeveloped reserves in Sulige tight sandstone gas reservoir[J]. Lithologic Reservoirs, 32(04):115-1. 